Agriculture, Agrobusiness and Biotechnology

Vol.59: e17160288, January-December 2016 http://dx.doi.org/10.1590/1678-4324-201616028 8 ISSN 1678-4324 Online Edition

\title{
Efficient In Vitro Somatic Embryogenesis and Plant Regeneration from Mature and Immature Embryos of Wheat (Triticum aestivum L.)
}

\author{
Roghayeh Ahmadpour ${ }^{1}$, Nasser Zare ${ }^{\mathbf{1}, *}$, Rasool Asghari-Zakarta ${ }^{1}$, Parisa Sheikhzadeh ${ }^{\mathbf{1}}$. \\ ${ }^{1}$ Department of Agronomy and Plant Breeding, Faculty of Agriculture, University of Mohaghegh Ardabili, Ardabil, \\ Iran.
}

\begin{abstract}
An efficient regeneration system is a pre-requisite for the application of genetic transformation and functional genomics study of important plants. In this study, the effect of different factors (plant growth regulators, casein hydrolysate, aspartic acid and ascorbic acid) on in vitro embryogenesis and regeneration of Arta, Bahar and Zagros cultivars from mature and immature explants were investigated. Immature and mature embryos were dissected from disinfected seeds 20-25 days after pollination and imbedded mature seeds, respectively, and cultured on MS (Murashige and Skoog) medium supplemented with different compounds. The results showed that immature embryos expose high capacity of embryogenesis and regeneration in comparison with mature embryos. There were significant differences between cultivars in terms of the percentage of callus induction and regeneration. Plant growth regulators had significant effect on percentage of callus induction in mature explants and percentage of regeneration from both explants. In immature explants, the highest percentage of regeneration (65\%) was achieved with the Arta cultivar calli derived from MS medium supplemented with $1 \mathrm{mg} / \mathrm{L}$ 2,4-D, $2 \mathrm{mg} / \mathrm{L}$ Picloram and $200 \mathrm{mg} / \mathrm{L}$ casein hydrolysate, and subcultured on MS medium. Also, the highest percentage of regeneration (52.38\%) from mature embryo explants was achieved in the Arta cultivar with callus induction on MS medium supplemented with $1 \mathrm{mg} / \mathrm{L} \mathrm{2,4-D,2} \mathrm{mg} / \mathrm{L}$ Picloram and $200 \mathrm{mg} / \mathrm{L}$ casein hydrolysate and regeneration on MS medium containing $0.05 \mathrm{mg} / \mathrm{L} N \mathrm{NA}$.
\end{abstract}

Key words: In vitro culture, Plant growth regulators, Somatic embryogenesis, Wheat

\footnotetext{
*Author for correspondence: zarenasser@yahoo.com, nzare@uma.ac.ir
} 


\section{INTRODUCTION}

Wheat is one of the most important cereals. It cultivates on approximately $17 \%$ of the cultivatable lands and plays a key role in economic development, food security and supply, human nutrition and is an important source of calories and proteins for human [1]. While, genetic engineering of wheat provides an efficient strategy for improvement of agronomic traits such as quality and disease resistance, but the graminaceous species are recalcitrant to in vitro regeneration and manipulations $[2$, 3]. An efficient regeneration system is the main pre-requisite for the application of genetic transformation and functional genomics studies in the primomovente of important plants [4]. Somatic embryogenesis is also an important step in transformation, regeneration and rapid large scale production of healthy true-to-type plants $[1,5]$. Somatic embryogenesis provide a perfect system for plant regeneration because embryogenic calli can be maintained for a long time and supply high multiplication rates [6]. Wheat is a hexaploid plant with a large genome, high copy number of DNA repeat sequences, low in vitro regeneration capability and difficult transformation features [7]. Therefore, one of the main limiting factors for application of biotechnological techniques in the genetic improvement of wheat is the lack of an efficient in vitro regeneration system for broad range of cultivars and genotypes [3]. On the other hand, establishment of an efficient regeneration system is necessary for the genetic engineering of wheat.

The explants source, genotype and medium composition were shown to influence the frequency of callus induction and regeneration in the wheat tissue culture [8-11]. In particular, genotype and explants type are important factors for embryogenic callus production and regeneration [12]. The studies showed that, the successful in vitro regeneration of wheat plantlets is possible from different explants such as immature embryos, mature embryos, inflorescences, anthers, and microspores [13-15]. Immature embryos were used in several regeneration and transformation studies and it has better regeneration potential than the other explants such as inflorescence, mature embryo and apical meristem [16]. But the production of immature embryo is limited by environmental conditions such as light, temperature, water, diseases, pests, growth periods and etc. The use of mature embryo has several advantages including easy handling, no time limitation and its availability in large scale [3]. Therefore, mature embryos suggested as a suitable explants for in vitro regeneration and genetic manipulation of cereals. [4]. Medium compositions such as plant growth regulators are important factors affecting callus induction and in vitro regeneration. The auxin 2,4-D (2,4-Dichlorophenoxyacetic acid) is commonly used for callus induction in cereals as well as wheat $[7,17]$. The aim of this study was optimization of in vitro regeneration of Iranian different wheat cultivars using immature and mature embryos. Therefore, the effect of different plant growth regulators on callus induction, somatic embryogenesis and plant regeneration from three wheat cultivars were investigated.

\section{MATERIALS AND METHODS}

\section{Plant materials}

Seeds of wheat cultivars (Arta, Bahar and Zagros) were obtained from the Seed and Plant Improvement Institute, Karaj, Iran. For immature embryo explants preparation, the seeds were planted in the pots and maintained in a greenhouse at $21 \pm 2{ }^{\circ} \mathrm{C}$ with a $16 \mathrm{~h}$ photoperiod. The immature seeds were collected 20-25 days after pollination and surface sterilized with $70 \%$ (v/v) ethanol for 30-45 seconds, $2 \%(\mathrm{w} / \mathrm{v})$ sodium hypochlorite solution for $13-15 \mathrm{~min}$ and rinsed three times with sterile distilled 
In vitro Regeneration of Wheat

water. Immature embryos were excised from sterilized immature seeds and cultured on medium.

For mature embryo explants preparation, the mature seeds of wheat were surface sterilized with $70 \%(\mathrm{v} / \mathrm{v})$ ethanol for $3 \mathrm{~min}, 2 \%(\mathrm{w} / \mathrm{v})$ sodium hypochlorite for 20 min and rinsed three times with sterile distillated water. The seeds were soaked with sterile distillated water overnight at $25^{\circ} \mathrm{C}$ in the dark and then, mature embryos were excised and cultured on medium.

\section{Embryogenic callus induction}

In order to embyogenic callus induction, the immature and mature embryos were cultured scutellum up on MS (Murashige and Skoog) medium supplemented with different concentrations of 2,4-D, Picloram, and organic additives such as casein hydrolysate, aspartic acid and ascorbic acid (Table 1). Twenty five embryos were cultured in each Petri-dish. The cultures were maintained in a growth chamber at 25 $\pm 2{ }^{\circ} \mathrm{C}$ and dark for three weeks. Then, the percentage of callus induction, embryogenic callus and callus fresh weights were recorded.

Table 1. Culture medium used for callus induction from mature and immature embryos of wheat.

\begin{tabular}{ll}
\hline Induction medium & Composition \\
\hline IM1 & MS+2 mg/L 2,4-D+150 mg/L Aspartic acid \\
IM2 & MS+2 mg/L 2,4-D+100 mg/L Ascorbic acid \\
IM3 & MS+2 mg/L 2,4-D+200 mg/L Casein hydrolysate \\
IM4 & MS+1 mg/L 2,4-D+2 $\mathrm{mg} / \mathrm{L}$ Picloram+150 mg/L Aspartic acid \\
IM5 & MS+1 mg/L 2,4-D+2 mg/L Picloram+100 mg/L Ascorbic acid \\
IM6 & MS+1 mg/L 2,4-D+2 mg/L Picloram+200 mg/L Casein hydrolysate \\
IM7 & MS+2 mg/L 2,4-D+1 mg/L Picloram+150 mg/L Aspartic acid \\
IM8 & MS+2 mg/L 2,4-D+1 mg/L Picloram+100 mg/L Ascorbic acid \\
IM9 & MS+2 mg/L 2,4-D+1 mg/L Picloram+200 mg/L Casein hydrolysate \\
IM10 & MS+4 mg/L 2,4-D+150 mg/L Aspartic acid \\
IM11 & MS+4 mg/L 2,4-D+100 mg/L Ascorbic acid \\
IM12 & MS+4 mg/L 2,4-D+200 mg/L Casein hydrolysate \\
\hline
\end{tabular}

\section{Plant regeneration}

After 3 weeks, the calli obtained from immature and mature embryos were subcultured on regeneration medium. The regeneration medium consisted of MS medium without hormone (RM1, Table 1) and supplemented with $0.05 \mathrm{mg} / \mathrm{L}$ NAA (Naphthalene acetic acid) (RM2, table 1). The cultures were maintained in a growth chamber at $25 \pm 2{ }^{\circ} \mathrm{C}$ and $16 \mathrm{~h}$ photoperiods. Percentage of rooting and regeneration of plantlets were recorded after three weeks after culture. For further growth, the regenerated plantlets were transferred to MS medium for three weeks and then to pots containing sterilized Peat Moss, and were kept in a high humidity conditions under plastic bags for adaptation. In all cases, the $\mathrm{pH}$ of medium was adjusted to 5.8, solidified with $8 \mathrm{~g} / \mathrm{L}$ plant agar and autoclaved at $121.5^{\circ} \mathrm{C}$ for $15 \mathrm{~min}$. The explants and calli were cultured on $30 \mathrm{ml}$ of medium in $100 \times 25 \mathrm{~mm}$ Petri plates and wrapped with Parafilm.

\section{Experimental design and data analysis}

All experiments were performed as factorial experiment based on completely randomized design (CRD) with three replications and 25 explants per replicate. Data analyses were performed using IBM SPSS Statistics (Version 22.0 (Armonk, NY, USA)). Mean comparisons were carried out using Least Significant Difference (LSD) and Duncan's multiple range test at probability level of 0.05 . 


\section{RESULTS}

\section{Callus induction from immature embryo explants}

Callus induction response was quick, so that most of the explants exhibited rapid swelling and cell proliferation 3-4 days after culture leading to the formation of friable embryogenic yellow callus within 1-2 weeks (Fig. 1C). Analysis of variance (ANOVA) indicated that there was significant differences $(p<0.01)$ between the wheat cultivars in percentage of callus induction. But callus induction medium and its interaction with cultivar did not show significant effects on the percentage of callus induction. All of the tested cultivars displayed a high percentage of callus induction (97.58-100\%) 21 days after culture. The Zagros cultivar showed an excellent (100\%) callus induction frequency (Fig. 2A).

Callus fresh weight was significantly influenced by interaction of callus induction medium and cultivar, while medium and cultivar did not show significant effect on this trait. The mean of callus fresh weight ranged from 46.64 to $132.89 \mathrm{mg}$ per callus. The highest amount of callus fresh weight $(132.89 \mathrm{mg})$ was achieved with Arta cultivar on MS medium supplemented with $2 \mathrm{mg} / \mathrm{L} \mathrm{2,4-D} \mathrm{and} 200 \mathrm{mg} / \mathrm{L}$ casein hydrolysate (Fig. 3).

\section{Plant regeneration from immature embryo explants}

About 3 weeks after culture of immature embryos, the calli were transferred to the regeneration medium. According to the ANOVA results, the percentage of embryogenic callus was significantly influenced by different callus induction medium and their interaction with cultivars. While it not influenced by cultivars, regeneration medium and their interactions. Among different callus induction medium, the highest percentage of embryogenesis achieved from the calli derived from the IM7, IM9 and IM12 media (Table 1 and Fig. 2B).

Different stages of somatic embryogenesis and plantlet regeneration were shown in fig. 1 . The results indicated that the percentage of rooting were significantly $(p<0.01)$ affected by cultivar, callus induction medium and their interaction. But there were no significant differences between different regeneration media. The percentage of rooting in the Arta cultivar (87.45\%) was significantly higher than that of the Bahar and Zagros cultivars. In addition, the highest percentage of rooting in the Arta cultivar was obtained with IM1 and IM4; with IM7 in the Bahar cultivar and with IM1, IM2 and IM6 in the Zagros cultivar (Table 2). Therefore, in the Arta and Bahar cultivars the combination of low concentrations of 2,4-D with aspartic acid were more effective on rooting as compared with their combinations with ascorbic acid and casein hydrolysate.

The percentage of plant regeneration significantly affected by cultivar, callus induction medium, and cultivar $\times$ callus induction medium and cultivar $\times$ callus induction medium $\times$ regeneration medium interactions. While, there was no significant differences between various regeneration medium. The percentage of regeneration in the Arta cultivar (36.02\%) was higher than that of the others. Overall, the low concentration of 2,4-D in combination with casein hydrolysate had favorable effect on regeneration, so that, MS medium supplemented with $1 \mathrm{mg} / \mathrm{L}$ 2,4-D, $2 \mathrm{mg} / \mathrm{L}$ Picloram and $200 \mathrm{mg} / \mathrm{L}$ casein hydrolysate (IM6) showed the highest percentage of plant regeneration (Table 2). The highest percentage of plant regeneration in the Arta cultivar (65\%) was obtained with the calli derived from IM6 callus induction medium and subcultured on RM1 (MS medium without hormone) regeneration medium. But, the highest percentage of regeneration in the Bahar (51.59\%) and Zagros (47.78\%) cultivars were obtained with the calli derived from IM11 and IM1 induction medium and subcultured on RM2 (MS medium containing $0.05 \mathrm{mg} / \mathrm{L}$ NAA) regeneration medium, respectively (Table 2). 
In vitro Regeneration of Wheat

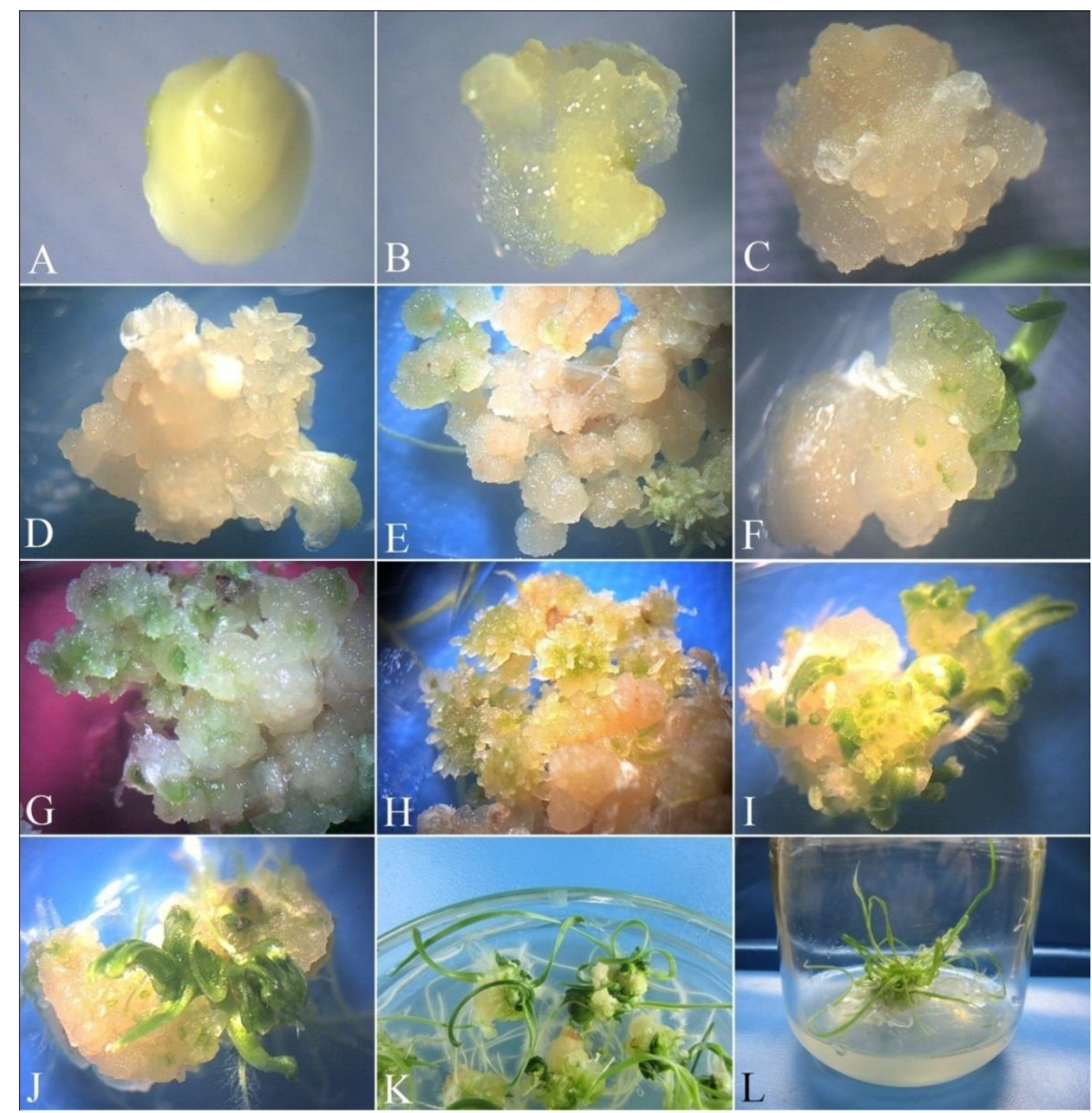

Figure 1. Different stages of somatic embryo induction and development from immature embryos of wheat. A) Immature embryo, B) Callus formation 3-4 days after culture on callus induction medium, C) Embryogenic callus, D,E,F) Different stages of somatic embryo development, G, H, I) Different stages of rooting and initiation of shoot formation, J, K) Plantlets regeneration 2 and 3 weeks after transferring to regeneration medium, L) Regenerated plantlet on MS medium

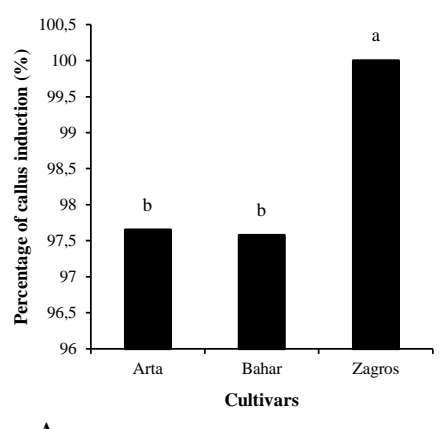

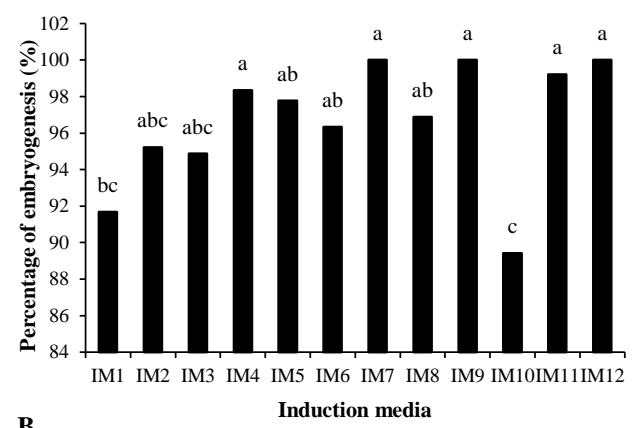

Induction media

Figure 2. A) Percentage of callus induction from immature embryos of different wheat cultivars. B) Effect of different callus induction medium on percentage of embryogenesis from immature embryos of wheat 
Table 2. The effect of different cultivars, callus induction and regeneration medium on plantlet regeneration and rooting of wheat immature embryos

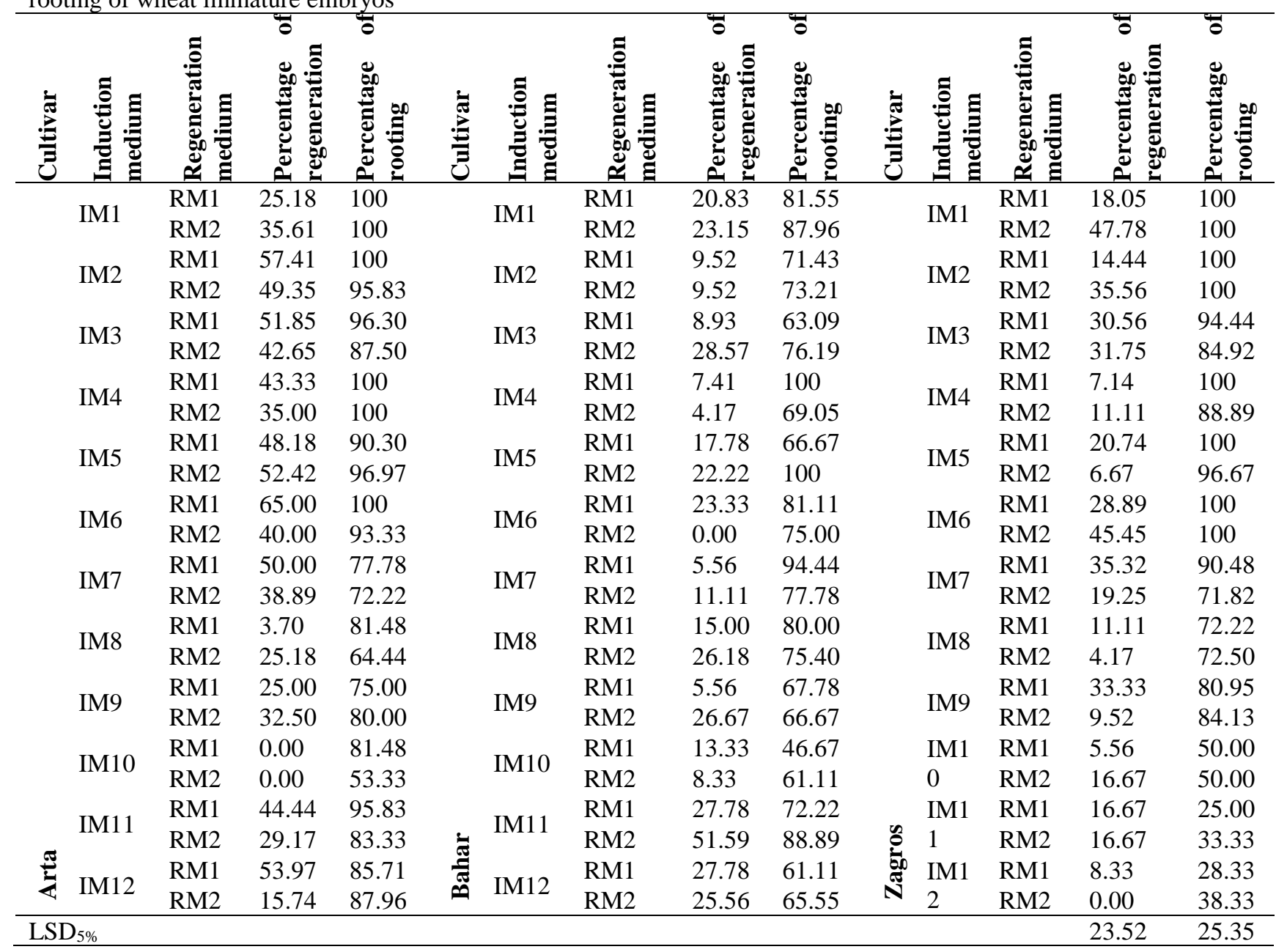

Callus induction from mature embryo explants

The results indicated that, the percentage of callus induction from mature embryos significantly $(p<0.01)$ affected by cultivar, callus induction medium and their interaction. The mean percentage of callus induction ranged from $96.21 \%$ in the Zagros cultivar to $100 \%$ in the Bahar cultivar. As shown in fig. 3, the callus induction of Zagros cultivar in the MS medium supplemented with $2 \mathrm{mg} / \mathrm{L} \mathrm{2,4-D}$ and $150 \mathrm{mg} / \mathrm{L}$ aspartic acid (IM1), and MS medium supplemented with $1 \mathrm{mg} / \mathrm{L} \mathrm{2,4-}$ D, $2 \mathrm{mg} / \mathrm{L}$ Picloram and $200 \mathrm{mg} / \mathrm{L}$ casein hydrolysate (IM6) were significantly lower than those of other cultivars. While, the percentage of callus induction of cultivars on the other callus induction medium did not significantly different from each others. It means that, the effect of different compounds depended upon the cultivar (Fig. 4). Although the callus fresh weight was not significantly influenced by cultivar, callus induction medium and their interaction. The mean of callus fresh weight was varied from $80.63 \mathrm{mg}$ in the Arta cultivar to $93.74 \mathrm{mg}$ in the Zagros cultivar. Also, the response of different cultivars to various callus induction media were different. 


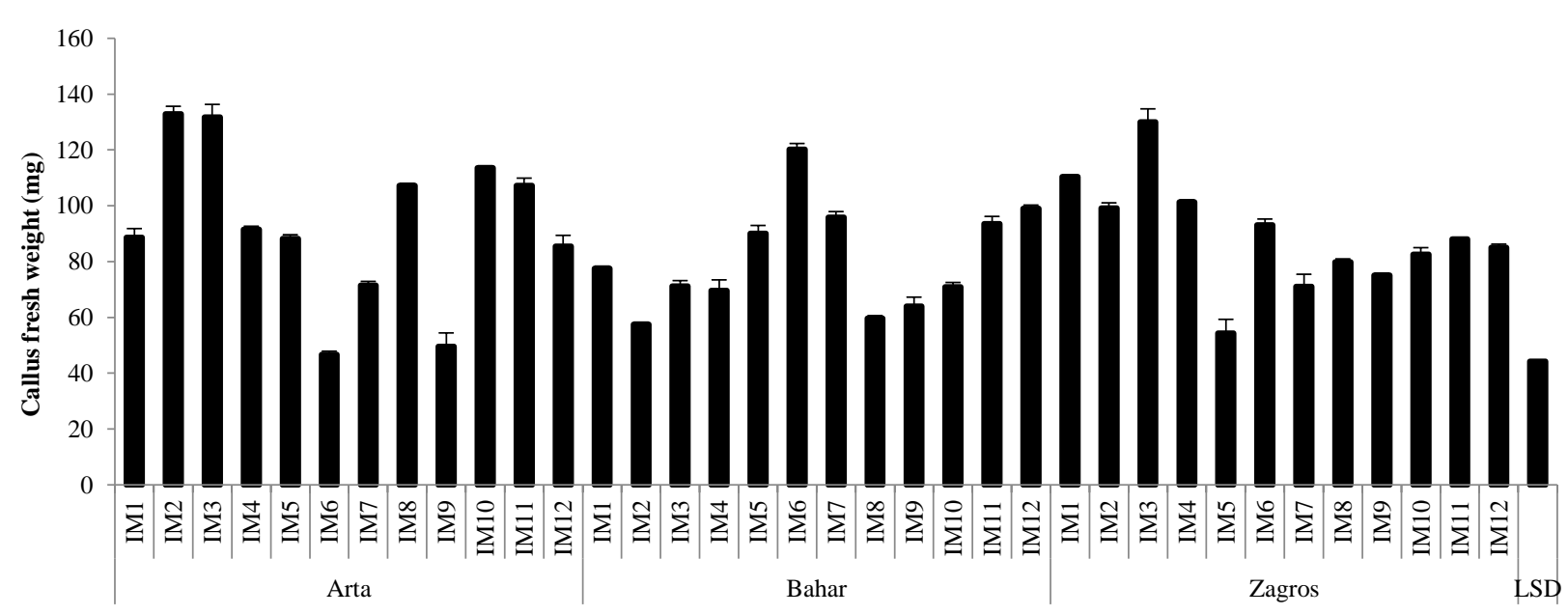

Cultivars and induction media

Figure 3. Effect of different callus induction medium on callus fresh weight from immature embryos of wheat cultivars

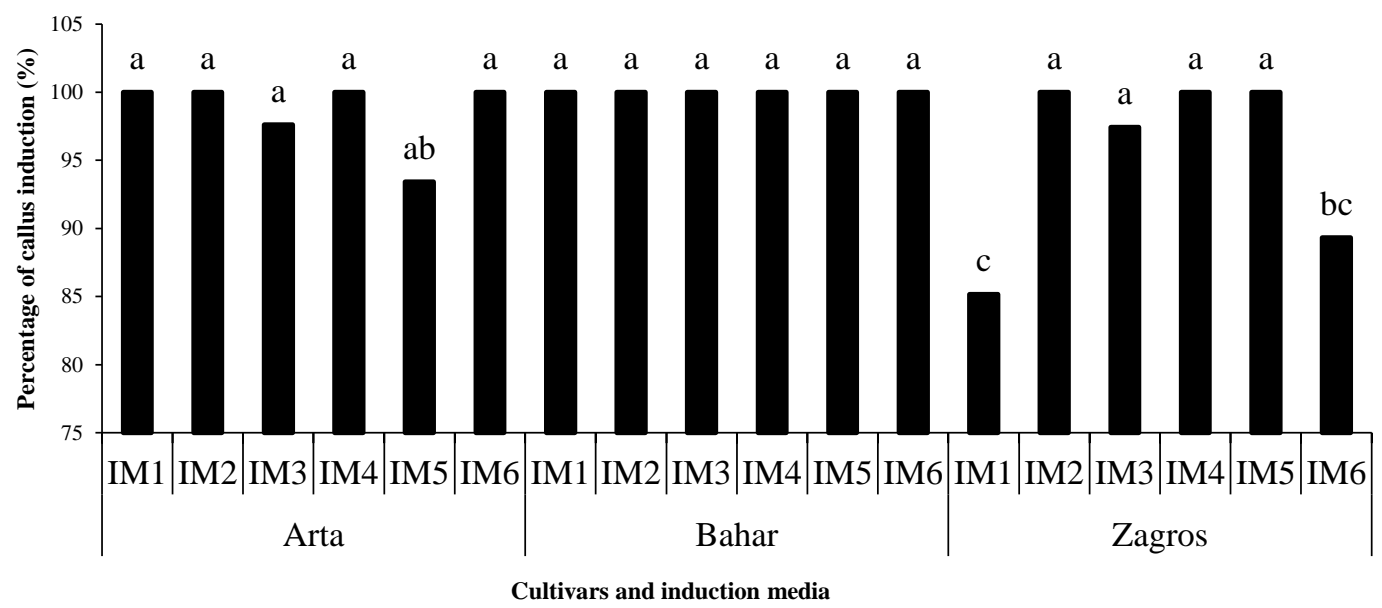

Figure 4. Effects of different cultivars and callus induction medium on percentage of callus induction from mature embryos of wheat

\section{Plant regeneration from mature embryo explants}

The results indicated that there were no significant differences in the percentage of embryogenic callus between different cultivars, callus induction and regeneration media. The percentage of embryogenic callus ranged from $86.67 \%$ to $100 \%$. Root formation (Rooting) from the most of the embryogenic calli was occurred after transferring to the regeneration medium. According to the ANOVA, percentage of rooting after transferring to regeneration medium was significantly $(p<0.01)$ affected by cultivar, callus induction medium and their interaction, but did not significantly different between regeneration media. Overall, the percentage of rooting in the Bahar cultivar was higher than that of the other cultivars. As shown in table 3 , addition of casein hydrolysate to callus induction medium decreased the percentage of rooting in the Arta and Zagros cultivars. However, in the Arta cultivar the presence of picloram in the callus induction medium (IM6) compensate the negative effects of casein hydrolysate on rooting (Table 3 ).

The percentage of plant regeneration was only affected by callus induction medium. While, there were no significant differences between different cultivars and 
regeneration medium with respect to regeneration capability. The average of regeneration percentage was varied from 6.67 to $52.38 \%$. Overall, among the tested callus induction medium, the highest percentage of plant regeneration was occurred on MS medium containing $1 \mathrm{mg} / \mathrm{L} \mathrm{2,4-D,} 2 \mathrm{mg} / \mathrm{L}$ Picloram and $200 \mathrm{mg} / \mathrm{L}$ casein hydrolysate (Fig. 5). The highest percentage of plant regeneration in the Arta (52.38\%), Bahar (44.44\%) and Zagros $(27.78 \%)$ cultivars were obtained on RM2 regeneration medium from the calli derived from IM6, IM4 and IM3 callus induction medium, respectively (Table 3).

Table 3. Effect of different cultivars, callus induction and regeneration medium on regeneration and rooting of wheat mature embryos

\begin{tabular}{|c|c|c|c|c|c|c|c|c|c|c|c|c|c|}
\hline 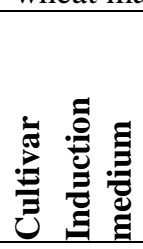 & 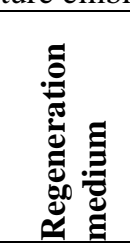 & 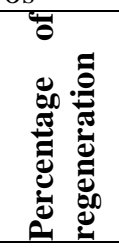 & 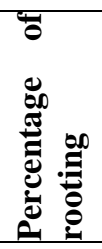 & 苞 & : & 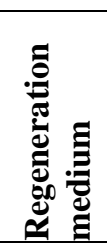 & 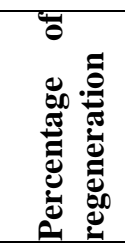 & 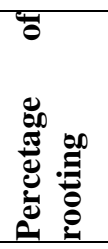 & 莞 & 异 & 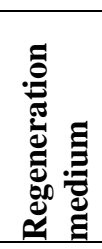 & 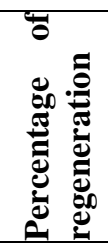 & 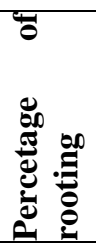 \\
\hline \multirow{2}{*}{ IM1 } & RM1 & 23.81 & 85.71 & & \multirow{2}{*}{ IM1 } & RM1 & 14.29 & 73.81 & \multirow{2}{*}{\multicolumn{2}{|c|}{ IM1 }} & RM1 & 10.37 & 100 \\
\hline & RM2 & 26.19 & 95.24 & & & RM2 & 16.67 & 83.33 & & & RM2 & 14.81 & 100 \\
\hline \multirow{2}{*}{ IM2 } & RM1 & 13.33 & 100 & & \multirow{2}{*}{ IM2 } & RM1 & 25.00 & 100 & \multirow{2}{*}{\multicolumn{2}{|c|}{ IM2 }} & RM1 & 23.21 & 95.24 \\
\hline & RM2 & 31.11 & 100 & & & RM2 & 8.33 & 100 & & & RM2 & 19.05 & 100 \\
\hline \multirow{2}{*}{ IM3 } & RM1 & 9.52 & 50.00 & & \multirow{2}{*}{ IM3 } & RM1 & 33.33 & 100 & \multirow{2}{*}{\multicolumn{2}{|c|}{ IM3 }} & RM1 & 15.08 & 95.24 \\
\hline & RM2 & 10.32 & 54.76 & & & RM2 & 8.33 & 100 & & & RM2 & 27.78 & 72.22 \\
\hline \multirow{2}{*}{ IM4 } & RM1 & 20.00 & 100 & & \multirow{2}{*}{ IM4 } & RM1 & 25.00 & 100 & \multirow{2}{*}{\multicolumn{2}{|c|}{ IM4 }} & RM1 & 20.00 & 100 \\
\hline & RM2 & 26.67 & 100 & & & RM2 & 44.44 & 100 & & & RM2 & 6.67 & 100 \\
\hline \multirow{4}{*}{$\sum_{2}^{\pi}$ IM6 } & RM1 & 16.06 & 94.66 & & \multirow{2}{*}{ IM5 } & RM1 & 27.98 & 100 & \multirow{4}{*}{ 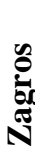 } & \multirow{2}{*}{ IM5 } & RM1 & 13.33 & 100 \\
\hline & RM2 & 31.67 & 96.67 & \multirow{3}{*}{ صี } & & RM2 & 22.29 & 92.59 & & & RM2 & 8.33 & 93.33 \\
\hline & RM1 & 33.33 & 100 & & \multirow{2}{*}{ IM6 } & RM1 & 37.30 & 100 & & \multirow{2}{*}{ IM6 } & RM1 & 20.83 & 71.21 \\
\hline & RM2 & 52.38 & 100 & & & RM2 & 33.33 & 100 & & & RM2 & 22.62 & 91.07 \\
\hline $\mathrm{LSD}_{5 \%}$ & & & & & & & & & & & & 26.22 & 15.09 \\
\hline
\end{tabular}

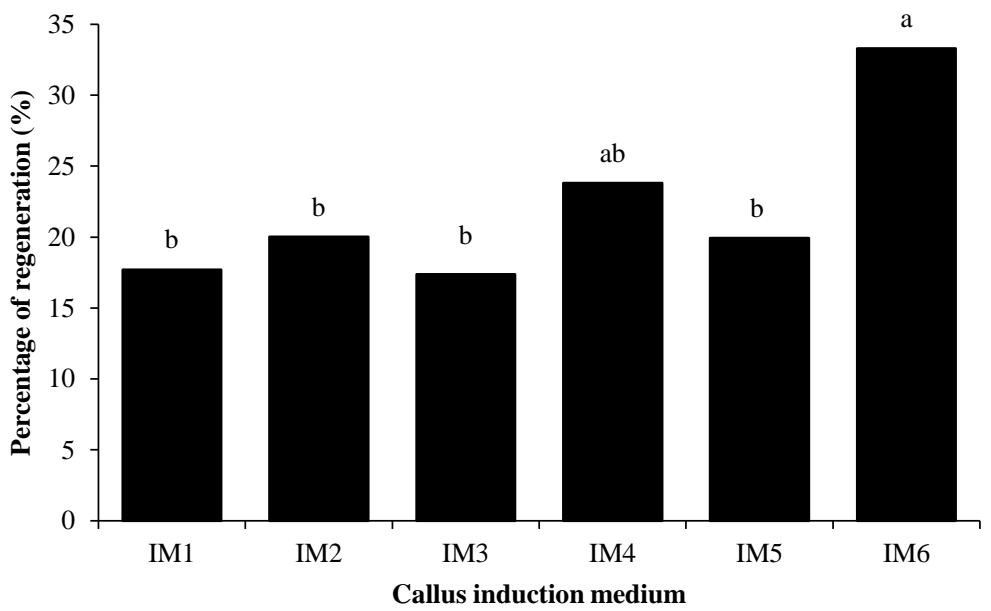

Figure 5. Effect of different callus induction medium on plantlet regeneration from mature embryo-derived calli in wheat

\section{DISCUSSION}

It has been reported that the frequency of callus induction and in vitro regeneration in wheat are highly dependent on the plant genotype and its interaction with regeneration protocol $[6,17]$. Optimization of an efficient in vitro regeneration system is a prerequisite for the protocols which currently used for successful genetic 
In vitro Regeneration of Wheat

transformation of wheat cultivars. This situation limits the application of biotechnological techniques for the genetic improvement of wheat cultivars. In the present study, in vitro regeneration of three Iranian wheat cultivars was achieved using mature and immature embryos, different callus induction and regeneration medium. Different cultivars showed substantial differences in the ability of embryogenic callus induction, callus growth (fresh weight of callus), rooting and regeneration. The variation in regeneration efficiency of genotypes could be attributed to the differences in genetic programming and reprogramming of embryogenically cells, which usually influenced by different external factors [8]. Therefore, we used different external factors such as different callus induction and regeneration medium compositions to overcome the genotype influence and increase the plant regeneration efficiency. Cultivars exhibited different percentage of embryogenesis and regeneration on different induction and regeneration medium, but regeneration capacity was still genotype dependent. The Arta cultivar showed higher regeneration ability than others (Table 2 and 3). This result is consistent with the reports of Sears and Deckard [18] and Özgen et al. [19]. Filippov et al. [8] reported that overall morphogenic capacity of different genotypes of spring and winter wheat dependent on genotype. Bi et al. [20] have been compared different genotypes of wheat and reported significant difference in callus induction, embryogenic callus differentiation, plantlet regeneration and culture efficiency.

Immature embryos are most favorable explant for efficient regeneration of whole plants [21, 22]. Thus, in most reports on transgenic wheat plant production, immature embryos are utilized as explant for delivery of foreign DNA [23]. It is difficult to obtain immature embryos throughout the year, and their suitable stages for culture are also limited [19]. But, mature embryos are available at all times but they were not frequently used for embryogenic culture initiation because of their low frequencies of callus induction [24, 25]. In this study immature and mature embryos were tested for somatic embryogenesis and regeneration of the three cultivars of wheat. In general, the frequency of callus induction and callus growth (callus fresh weight) of the wheat cultivars from immature embryos were better than from mature embryos (Fig. 2, 3, 4 and 5). This result is consistent with Khurana et al. [26]. They showed that immature embryo had higher callus formation than mature embryo. On the contrary, Özgen et al. [19] reported that mature embryo had high callus induction frequency.

The overall average of plant regeneration percentage in the calli formed from immature embryos was $24.43 \%$ and in calli formed from mature embryos was $22.02 \%$. Thus, there was no considerable significances between the overall regeneration capacity of immature and mature embryos (Table 2 and 3). High regeneration efficiency with using immature embryo in bread wheat have been reported by Rasco-Gaunt et al. [27] and Ozias-Akins and Vasil [28], while Khurana et al. [26] reported lower regeneration ability in immature embryos than mature embryos.

Plant growth regulators are other important factors affecting callus induction and somatic embryogenesis in plant tissue cultures [3, 29]. The auxin type and concentration is the most important factor of medium which determines the somatic embryogenesis in the cereals [9]. In most studies, the researchers used 2,4-D as an exogenous auxin for callus induction and somatic embryogenesis of wheat and other cereals $[19,30]$. 2,4-D was used successfully for callus induction in numerous experiments but this type of auxin at higher concentrations increases chromosomal instability and cause to somaclonal variation [31]. Therefore, in subsequent studies dicamba and picloram were used instead of 2,4-D [32]. In this study, two different synthetic auxins (2,4-D and picloram) in combination and alone were used for callus 
induction and somatic embryogenesis. Since higher concentration of 2,4-D had negative effect on somatic embryo development, low concentration of 2,4-D in combination with high concentration of picloram, were used for callus induction and somatic embryogenesis. As a result, the highest percentage of plant regeneration was obtained from embryogenic calli induced on MS medium supplemented with $1 \mathrm{mg} / \mathrm{L}$ 2,4-D, $2 \mathrm{mg} / \mathrm{L}$ picloram and $200 \mathrm{mg} / \mathrm{L}$ casein hydrolysate (Table 2 and 3). This results is consistent with the reports of Przetakiewicz et al. [9]. They reported that dicamba alone or in combination with picloram and 2,4-D were the best medium for embryogenic callus formation in the wheat genotypes. Kachhwaha et al. [33] compared the picloram and 2,4-D effects on somatic embryogenesis and plant regeneration of barley and showed that picloram gave much better results. Tao et al. [16] reported that substitution of 2,4-D with dicamba enhances the growth and regeneration capacity of wheat. Kordestani and Karami [34] reported that the maximum embryogenesis in strawberry was obtained by using $2 \mathrm{mg} / \mathrm{L}$ picloram.

\section{CONCLUSION}

We evaluated the in vitro regeneration of wheat cultivars using mature and immature embryos. In general, the frequency of plant regeneration from immature embryos was slightly higher than that of mature embryos. But, cultivation of Arta and Bahar mature embryos on embryogenic callus induction medium IM6 and IM4, respectively, and subculture of the embryogenic calli on RM2 (MS medium supplemented with $0.05 \mathrm{mg} / \mathrm{L}$ NAA) led to relatively high plantlet regeneration frequency, which was comparable with their regeneration frequency using immature embryos. Thus, with regard the availability of mature embryos throughout the year, this protocol can be used for clonal propagation and genetic transformation of wheat cultivars.

\section{REFERENCES}

1. Jones HD. Wheat transformation: current technology and applications to grain development and composition. J Cereal Sci. 2005; 41(2): 137-147.

2. Karthikeyan A, Pandian S, Ramesh M. High frequency plant regeneration from embryogenic callus of a popular indica rice (Oryza sativa L.). Physiol Mol Biol Plants. 2009; 15(4): 371-375.

3. Ren J-p, Wang X-g, Yin J. Dicamba and sugar effects on callus induction and plant regeneration from mature embryo culture of wheat. Agr Sci China. 2010; 9(1): 31-37.

4. Yin G-X, Wang Y-1, She M-y, Du L-p, Xu H-j, Ma J-X, Ye X-g. Establishment of a highly efficient regeneration system for the mature embryo culture of wheat. Agr Sci China. 2011; 10(1): 9-17.

5. Li J, Ye X, An B, Du L, Xu H. Genetic transformation of wheat: current status and future prospects. Plant Biotechnol Rep. 2012; 6(3): 183-193.

6. Mendoza M, Kaeppler H. Auxin and sugar effects on callus induction and plant regeneration frequencies from mature embryos of wheat (Triticum aestivum L.). In Vitro Cell Dev Biol-Plant. 2002; 38(1): 39-45.

7. Bhalla PL. Genetic engineering of wheat - current challenges and opportunities. Trends Biotechnol. 2006; 24(7): 305-311.

8. Filippov M, Miroshnichenko D, Vernikovskaya D, Dolgov S. The effect of auxins, time exposure to auxin and genotypes on somatic embryogenesis from mature embryos of wheat. Plant Cell Tiss Org. 2006; 84(2): 213-222.

9. Przetakiewicz A, Orczyk W, Nadolska-Orczyk A. The effect of auxin on plant regeneration of wheat, barley and triticale. Plant Cell Tiss Org. 2003; 73(3): 245-256.

10. Redha A, Talaat A. Improvement of green plant regeneration by manipulation of anther culture induction medium of hexaploid wheat. Plant Cell Tiss Organ. 2008; 92(2): 141146. 
In vitro Regeneration of Wheat

11. Tamás C, Szücs P, Rakszegi M, Tamás L, Bedő Z. Effect of combined changes in culture medium and incubation conditions on the regeneration from immature embryos of elite varieties of winter wheat. Plant Cell Tiss Org. 2004; 79(1): 39-44.

12. Machii H, Mizuno H, Hirabayashi T, Li H, Hagio T. Screening wheat genotypes for high callus induction and regeneration capability from anther and immature embryo cultures. Plant Cell Tiss Org. 1998; 53(1): 67-74.

13. Caswell K, Leung N, Chibbar R. An efficient method for in vitro regeneration from immature inflorescence explants of Canadian wheat cultivars. Plant Cell Tiss Organ. 2000; 60(1): 69-73.

14. Liu W, Zheng M, Konzak C. Improving green plant production via isolated microspore culture in bread wheat (Triticum aestivum L.). Plant Cell Rep. 2002; 20(9): 821-824.

15. Sharma VK, Hänsch R, Mendel RR, Schulze J. Influence of picloram and thidiazuron on high frequency plant regeneration in elite cultivars of wheat with long-term retention of morphogenecity using meristematic shoot segments. Plant Breeding. 2005; 124(3): 242246.

16. Tao L-1, Yin G-x, Du L-p, Shi Z-y, She M-y, Xu H-j, Ye X-g. Improvement of plant regeneration from immature embryos of wheat infected by Agrobacterium tumefaciens. Agr Sci China. 2011; 10(3): 317-326.

17. Cheng M, Lowe B, Spencer TM, Ye X, Armstrong C. Factors influencing Agrobacterium-mediated transformation of monocotyledonous species. In Vitro Cell Dev Biol-Plant. 2004; 40(1):31-45.

18. Sears R, Deckard E. Tissue culture variability in wheat: callus induction and plant regeneration. Crop Sci. 1982; 22(3): 546-550.

19. Özgen M, Türet M, Altınok S, Sancak C. Efficient callus induction and plant regeneration from mature embryo culture of winter wheat (Triticum aestivum L.) genotypes. Plant Cell Rep. 1998; 18(3-4):331-335.

20. Bi RM, Kou M, Chen LG, Mao SR, Wang HG. Plant regeneration through callus initiation from mature embryo of Triticum. Plant Breeding. 2007; 126(1): 9-12.

21. Hunsinger H, Schauz K. The influence of dicamba on somatic embryogenesis and frequency of plant regeneration from cultured immature embryos of wheat (Triticum aestivum L.). Plant Breeding. 1987; 98(2): 119-123.

22. Ozias-Akins P, Vasil I. Plant regeneration from cultured immature embryos and inflorescences of Triticum aestivum L. (wheat): Evidence for somatic embryogenesis. Protoplasma. 1982; 110(2): 95-105.

23. Lührs R, Lörz H. Plant regeneration in vitro from embryogenic cultures of spring- and winter-type barley (Hordeum vulgare L.) varieties. Theor Appl Genet. 1987; 75(1): 1625.

24. Ahmed KZ, Bartók T, Sági F. A modified method for rapid callus induction by utilization of endosperm metabolites in mature and immature seeds of bread wheat (Triticum aestivum L.) and durum wheat (Triticum durum L.). Cereal Res Commun. 1992; 20: 8186.

25. Bartók T, Sági F. A new, endosperm-supported callus induction method for wheat (Triticum aestivum L.). Plant Cell Tiss Org. 1990; 22(1): 37-41.

26. Khurana J, Chugh A, Khurana P. Regeneration from mature and immature embryos and transient gene expression via Agrobacterium-mediated transformation in emmer wheat (Triticum dicoccum Schuble). Indian J Exp Biol. 2002; 40(11): 1295-1303.

27. Rasco-Gaunt S, Riley A, Cannell M, Barcelo P, Lazzeri PA. Procedures allowing the transformation of a range of European elite wheat (Triticum aestivum L.) varieties via particle bombardment. J Exp Bot. 2001; 52(357): 865-874.

28. Ozias-Akins P, Vasil IK. Improved efficiency and normalization of somatic embryogenesis in Triticum aestivum (wheat). Protoplasma. 1983; 117(1): 40-44.

29. Farjaminezhad R, Zare N, Asghari-Zakaria R, Farjaminezhad M. Establishment and optimization of cell growth in suspension culture of Papaver bracteatum: a biotechnology approach for thebaine production. Turk J Biol. 2013; 37: 689-697.

30. Chen J-y, Yue R-q, Xu H-x, Chen X-j. Study on plant regeneration of wheat mature embryos under endosperm-supported culture. Agr Sci China. 2006; 5(8): 572-578. 
31. Ziauddin A, Kasha KJ. Long-term callus cultures of diploid barley (Hordeum vulgare). II. Effect of auxins on chromosomal status of cultures and regeneration of plants. Euphytica. 1990; 48(3): 279-286.

32. Satyavathi VV, Jauhar PP, Elias EM, Rao MB. Effects of growth regulators on in vitro plant regeneration in Durum wheat. Crop Sci. 2004; 44(5): 1839-1846.

33. Kachhwaha S, Varshney A, Kothari S. Somatic embryogenesis and long term high plant regeneration from barley (Hordeum vulgare L.) using picloram. Cereal Res Commun. 1997; 25(2): 117-126.

34. Kordestani GK, Karami O. Picloram-induced somatic embryogenesis in leaves of strawberry (Fragaria ananassa L.). Acta Biol Cracov Bot. 2008; 50(1): 69-72.

Received: February 03, 2016; Accepted: July 14, 2016 